\title{
Formas avançadas de dispersão urbana no vetor noroeste paulista: eixo São Paulo-Campinas
}

\author{
Advanced forms of urban sprawl in the northwest \\ vector of São Paulo: the São Paulo-Campinas Axis
}

Daniela Maria Eigenheer

Nadia Somekh

\section{Resumo}

Tempos de globalização e reestruturação produtiva configuram novos territórios metropolitanos que, na sua dispersão, incluem temporalidades históricas fragmentadas, globais e locais. Formas mais avançadas de urbanização em processo de constituição, indefinidas, superpostas, descontínuas, dispersas ou difusas apresentam contornos e limites territoriais nítidos, mas complexos do ponto de vista de suas relações espaciais. Apontamos neste artigo, a partir da década de 2000, dinâmicas de dispersão urbana diferenciadas, relacionadas com os avanços da econômica moderna, alterando os padrões de ocupação do tecido urbano ao longo do vetor Noroeste Paulista, eixo São Paulo-Campinas, estruturado pelas rodovias Anhanguera/Bandeirantes e considerado o mais importante vetor econômico do País. Esse processo fortalece um macroterritório estendido que requer reflexões sobre políticas públicas com nova abrangência.

Palavras-chave: dispersão urbana; infraestrutura; continuidade territorial.

\begin{abstract}
Globalization and productive restructuring shape new metropolitan territories that, in their sprawl, include fragmented historical times, global and local. More advanced shapes of urbanization undergoing a process of constitution, indefinite, overlapping, discontinuous, scattered or diffuse, present territorial boundaries that are clear but complex from the point of view of their spatial relations. This study analyzes, from 2000 onwards, new dynamics of urban sprawl, related to the advance of modern economy, that are changing the patterns of land use along the northwest vector of São Paulo, in the São PauloCampinas axis, structured by the Anhanguera/ Bandeirantes highways and considered Brazil's major economic vector. This process has strengthened an extended macro-territory that requires reflection on public policies with a new scope.
\end{abstract}

Keywords: urban sprawl; infrastructure; territorial continuity. 


\section{Introdução}

As tendências da urbanização incorporam transformações espaciais da economia, e o espaço capitalista produzido estrutura-se em redes de infraestrutura e é transformado, de acordo com os diferentes estágios deste processo de acumulação.

Objetiva-se, aqui, apontar a lógica e o impacto local e regional das novas dinâmicas de dispersão urbana que vem ocorrendo, no tecido urbano de territórios localizados no vetor noroeste paulista, a partir do século XXI, no contexto dos avanços da reestruturação produtiva da economia capitalista, ou seja, no contexto de um estágio mais avançado do processo de acumulação capitalista.

0 objeto deste artigo consiste na análise de um trecho de aproximadamente noventa quilômetros, compreendido entre a capital de São Paulo e o município de Campinas, estruturado pelo sistema de rodovias Anhanguera/ Bandeirantes e concentrador do segundo maior PIB do Estado, perdendo apenas para a capital.

Trata-se do mais importante eixo produtivo regional do estado de São Paulo, pois conecta as duas mais ricas regiões metropolitanas do estado: São Paulo (aproximadamente 20.5 milhões de habitantes) e Campinas (aproximadamente 3 milhões de habitantes). Além disso, do ponto de vista nacional, estabelece a principal conexão entre a maior metrópole do País, São Paulo, e a capita federal, Brasília.

A pesquisa concentra-se no eixo da rodovia Anhanguera, pois este apresenta maior concentração de ocupações ligadas ao setor terciário, ou seja, mais relacionadas aos avanços do processo de reestruturação produtiva.
Parte-se da hipótese de que este território, ao longo do eixo da rodovia Anhanguera, em sua forma atual, assume novos padrões de urbanização que se relacionam com um estágio mais avançado de acumulação capitalista, que intensifica as dinâmicas de dispersão e produz novas formas de tecido urbano ao longo do vetor noroeste paulista.

Ou seja, as transformações econômicas e sociais, necessárias para manutenção da acumulação da economia capitalista, têm gerado novas formas de organização social, que vêm produzido novas configurações e dimensões territoriais.

Observa-se que os municípios localizados no vetor noroeste estão inseridos em um mesmo contexto geográfico e econômico. Porém, apesar de inseridos em um mesmo eixo viário produtivo e incorporarem, nas dinâmicas urbanas de seus territórios, um estágio mais avançado do processo de reestruturação produtiva, pertencem a diferentes regiões administrativas. Valinhos e Vinhedo pertencem à região metropolitana de Campinas. Louveira (primeiro PIB per capita do estado) pertence à aglomeração urbana de Jundiaí. Cajamar está inserido na região metropolitana de São Paulo.

0 artigo aprofunda-se na observação empírica das transformações do tecido urbano dos municípios de pequeno porte, atravessados pelo eixo Anhanguera (Cajamar, Louveira, Valinhos e Vinhedo). 0 recente processo de urbanização desses municípios permitirá melhor evidenciar as recentes dinâmicas urbanas, que vêm produzindo alterações morfológicas e impactos regionais importantes.

Conforme Reis (2006, 2007, 2015), a análise do vetor noroeste se estrutura tendo 
Figura 1 - Eixo Anhanguera e o vetor Noroeste, inserção nacional, estadual e metropolitana
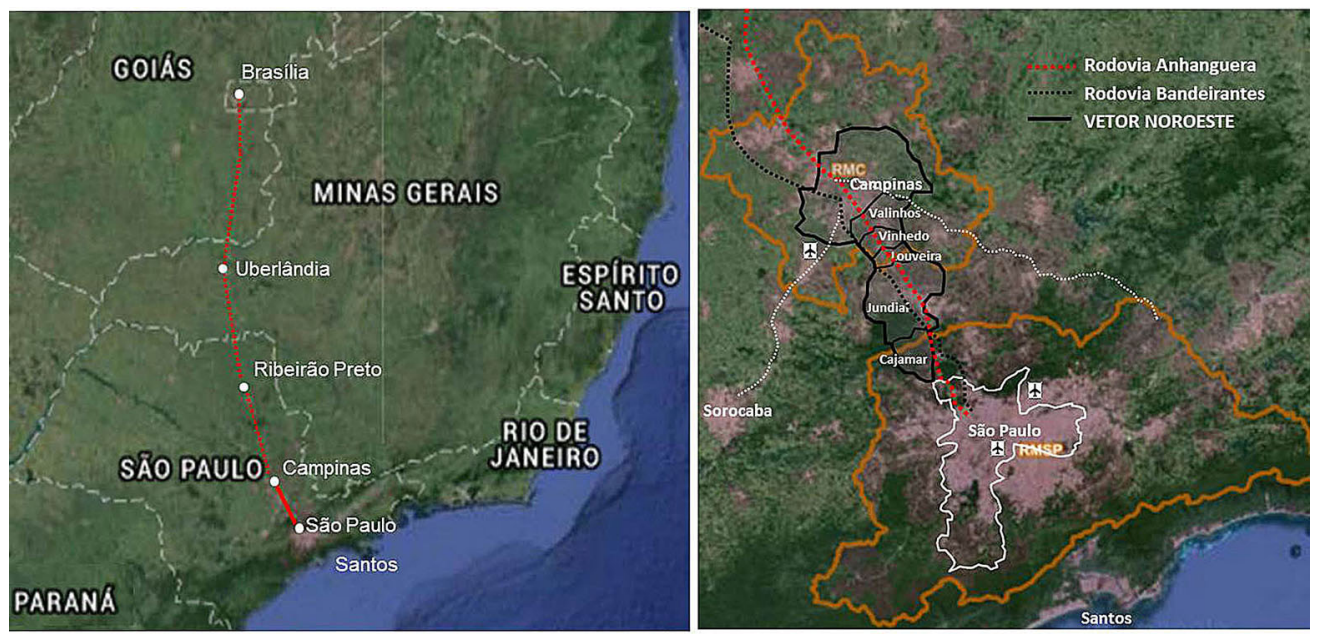

Fonte: Elaborado a partir de imagens da Emplasa Geo. Disponível em http://www.emplasageo.sp.gov.br, acesso em: 15 mar 2017.

em vista que, cada vez que se analisa uma determinada região, deve-se compreender que houve uma forma de desenvolvimento econômico relacionada a uma técnica ou infraestrutura correspondente e que esse espaço, além de produzido, é alterado e está em processo de transformação.

Ou seja, trata-se do processo de evolução de um eixo histórico que, desde o século XVIII, tem como principal função o transporte das riquezas entre o próspero interior, a capital e o porto de Santos. Os vários ciclos de desenvolvimento econômico desse vetor (ouro - século XVIII; café - século XIX; industrialização -1940/1950; desconcentração industrial -1970; reestruturação produtiva - 1990) foram possibilitados por diferentes infraestruturas cuja evolução técnica serviu como suporte espacial a esse desenvolvimento econômico e, ao mesmo tempo, permitiu que novas escalas urbanas se manifestassem nesse território (Eigenheer, 2011).

As dinâmicas de dispersão urbana têm início nesse vetor a partir de 1970, no contexto da desconcentração das atividades industriais, da capital rumo ao interior e outros estados. A seguir, partir de 1990, as dinâmicas de dispersão urbana são intensificadas no contexto da globalização e da reestruturação produtiva (Reis, 2006 e 2007).

Contudo, a partir de 2000, devido a intensificação e modernização dos processos anteriores, observa-se que novos aspectos morfológicos, distintos daqueles apresentados pelas tradicionais dinâmicas de dispersão urbanas, passam a caracterizar o tecido urbano dos municípios de pequeno porte localizados no eixo em estudo. 
Esse processo gera o fortalecimento de novas centralidades, bem como de um importante eixo urbano, produtivo e regional, estruturador de um macroterritório estendido ou da macrometrópole paulista, que requer novas formas de abordagem para sua gestão e monitoramento.

\section{Economia moderna e novas dinâmicas de dispersão urbana}

No contexto mundial e do ponto de vista econômico, transformações nos processos produtivos e evolução técnica são advindas do pós-guerra. A evolução dessas transformações constituirá, a partir de 1970, uma nova etapa do capitalismo, que viabilizará uma nova lógica territorial e espacial. A acumulação do capital não mais advirá da indústria tradicional, mas, agora, do setor de serviços advindo da modernização e fragmentação da indústria e do setor imobiliário e financeiro (Harvey, 1992).

No Brasil, ao longo do século XX, segundo Reis (2007), aconteceram algumas importantes mudanças no processo de urbanização, decorrentes de avanços técnicos e produtivos. A explosão demográfica resultante da melhoria das condições de vida, devido aos avanços da medicina e do saneamento, na virada do século XIX. A explosão urbana advinda da revolução industrial e das migrações campo-cidade. A explosão metropolitana decorrente da intensificação da industrialização e da implantação de infraestruturas viárias que permitiram uma nova espacialização da indústria consolidando os processos de metropolização e de dispersão industrial.
A continuidade dos processos de modernização e fragmentação industrial, ou seja, a explosão da multiplicação das áreas metropolitanas vinda da restruturação produtiva ou da universalização dos mercados e dos modos de produção, atrelada à globalização e às novas tecnologias de comunicação, consolidam as dinâmicas de dispersão urbana.

$E$, finalmente, decorrente da evolução do processo anterior, observa-se, no século XXI, a universalização dos modos de consumo padronizados em massa, que cada vez mais tem permitido a difusão do setor de serviços que passam a se organizar em rede, acarretando difusão também do modo de vida, bem como o estabelecimento de novas relações espaciais no território, objeto de estudo desta pesquisa.

Partindo do exposto, até o momento, parece clara a configuração de dois modelos do espaço capitalista. Um é decorrente do modo de produção industrial que levou à explosão urbana e à configuração do crescimento das metrópoles e de suas regiões metropolitanas. 0 outro, expressão espacial do capitalismo pós-industrial ou contemporâneo, é a extensão das regiões metropolitanas, que assumem novos contornos, devido às transformações econômicas e à nova configuração da indústria moderna, dando início às dinâmicas de dispersão urbana.

Esse processo de metropolização do espaço ou esse território estendido, caracterizado por dinâmicas de dispersão urbana, já foi bastante analisado por diversos autores, e é designado de diferentes formas.

No Brasil, vários autores abordam a reestruturação territorial e urbana advinda do processo de reestruturação produtiva instalado no País a partir de 1990: Regionalização do Espaço 
(Lencioni, 2004); Urbanização Dispersa (Reis, 2006); Urbanização Extensiva (Domingues, 2008); Urbanização Difusa (Spósito, 2009).

Essas múltiplas terminologias são influenciadas conforme o local onde a dinâmica é observada. Não se trata aqui de analisar qual conceito seja mais apropriado ou de sugerir uma definição mais adequada para as dinâmicas de dispersão urbana. Essas múltiplas definições servem para alertar sobre a complexidade dessas relações, e principalmente para mostrar que as dinâmicas de extensão territorial não são genéricas, universais nem estáticas, devendo, portanto, ser observadas e analisadas dentro do contexto e do tempo em que se inserem, a fim de que sejam planejadas e geridas de forma adequada e eficiente.

Lencioni (2004) atenta para a regionalização do espaço, o que implica a extensão das dinâmicas de áreas metropolitanas para outros territórios, que vão além de seus limites territoriais, tornando necessária uma reflexão voltada não mais sobre o contexto metropolitano, mas sobre a regionalização de áreas que se inserem em um mesmo contexto urbano e econômico.

Reis $(2006,2007)$ caracteriza a espacialização do fenômeno da dispersão urbana a partir do esgarçamento do tecido urbano e da constituição de nebulosas, tendo em vista a difusão dos modos de vida ou das relações sociais, bem como a dispersão industrial iniciada, a partir da década de 1970 no estado de São Paulo, e apoiada pelo avanço técnico de sua rede de infraestrutura rodoviária.

Para Reis (2006), tanto as razões de ordem técnica quanto a reorganização internacional do capitalismo (a reorganização produtiva) levaram à descentralização e à dispersão industrial.
Já Spósito (2009) denomina esse processo urbanização difusa, enfatizando mais a intensificação das novas dinâmicas de mobilidade, propiciadas pelas nova tecnologias de comunicação que ampliam e aceleram as formas de se deslocar e de se comunicar, produzindo descontinuidades territoriais. A cidade, em contraponto ao campo, encontra-se em processo de dissolução, em função do espraiamento do seu tecido urbano. Cada vez menos se percebe, com clareza, onde termina a cidade e onde começa o campo e cada vez mais se intensificam os fluxos.

Meyer (2015), ao abordar o processo paulista e paulistano de restruturação do território, caracteriza-o por uma acentuada descontinuidade territorial associada à dispersão de novos usos e à formação de novas centralidades, em que dois padrões se manifestam: fragmentação territorial e dispersão funcional. Enfatiza a necessidade do refinamento dessa análise, tendo em conta uma perspectiva histórica, ou seja, a evolução dos processos de expansão territorial da cidade, bem como o papel que a metrópole paulista exerce dentro do panorama do capitalismo global.

Segundo Pacheco (1998), da mesma forma que o desenvolvimento industrial determinou não apenas o ritmo de crescimento, mas muitas vezes a geografia do crescimento urbano da metrópole de São Paulo, embora esse processo também se relacione com seu passado cafeeiro, a partir da década de 1990, é o setor terciário metropolitano, advindo dos processos de reestruturação produtiva, que assume esse papel, transformando a metrópole industrial na metrópole dos serviços, trazendo reconfigurações espaciais e a extensão da escala metropolitana. 
Decorrente da restruturação produtiva, o que nos parece comum à constituição dessas novas escalas e formas de expansão urbana, sejam elas dispersas, difusas ou descontínuas, é sua estruturação, através de redes de infraestrutura físicas e virtuais. Estas possibilitam o descolamento físico de antigas áreas centrais consolidadas e a perda de continuidade e de unidade territorial que sempre caracterizaram as formações urbanas tradicionais, sejam elas metropolitanas ou simples aglomerações urbanas.

Do ponto de vista intraurbano e morfológico, a urbanização dispersa apresenta ausência de limites urbanos bem definidos, extensas ocupações territoriais com baixas densidades, vazios urbanos, reduzida coesão territorial, descontinuidade do tecido urbano e uma enorme fragmentação territorial e espacial, com produção de territórios contíguos que em sua grande maioria não se relacionam na escala local, mas estabelecem relações espaciais, muitas vezes bastante complexas.

Contudo, após 2010, tendo em vista a intensificação das dinâmicas de dispersão urbana no território, uma bibliografia mais recente aponta novos conceitos e dinâmicas urbanas.

Para Soja (2013), a era da metrópole moderna chegara ao fim. 0 autor aponta uma transição da urbanização metropolitana para a regional e, diante dessa transição pós-metropolitana, afirma que novos termos, como cidades-região e cidades regionais, crescerão em importância para a análise geográfica urbana ao longo da próxima década.

Para Lencioni (2015), as discussões atuais sobre aglomerações difusas, megalópole, metápolis, cidade-região, consideram esses espaços como região urbana e não como área urbana ou metropolitana. Para que uma área se constitua como uma região é necessário haver integração entre as partes.

A integração é que dá coesão ao que se apresenta disperso, para que se constitua uma totalidade, uma unidade ou uma região. Essa integração não é definida pela continuidade de elementos espaciais, mas pela integração que apresentam. Por isso, uma região pode apresentar descontinuidade territorial dos fenômenos desde que haja integração de diversas dinâmicas e processos que se desenvolvem em seu interior.

Sem a integração não seria possível visualizar os limites da dispersão e nem capturar as relações que são estabelecidas entre os fragmentos. É a integração que permite entender a tensão entre fragmentação e totalidade e que permite compreender que a dispersão significa dispersão de partes de um todo. (Lencioni, 2015, p. 9)

Portanto, para a autora, as nebulosas urbanas - urbanização dispersa cada vez mais extensiva territorialmente - apresentam sim limites e coesão espacial. É na identificação dessas partes que constituem uma unidade territorial, ou uma região, que devemos nos ater.

Assim, apontamentos como ausência de limites e de coesão espacial parecem não mais caracterizar as dinâmicas recentes de dispersão urbanas.

Brenner (2015) sugere questionamentos sobre a era urbana do nosso planeta e sobre a noção da divisão urbano/rural. Cada país mensura, através de seu censo, o que é o "urbano" em formas e com variáveis distintas.

Diferentes condições de urbanização precisam ser compreendidas, evitando-se, por exemplo, que as favelas de Mumbai ou os 
subúrbios de Melbourne sejam considerados em uma única contagem urbana, sem diferenciar suas reais condições, ou que áreas rurais na Índia, densamente povoadas, não sejam contempladas nessa contagem.

Denominadas pelo autor paisagem operacional, essas áreas rurais ou lugares remotos (Ártico, Sibéria, Himalaia, deserto do Saara e de Gobi) têm se tornado consideravelmente funcionais para o processo de urbanização extensiva, pois sustentam o crescimento ou as necessidades de abastecimento dos centros urbanos e, portanto, requererem estudos.

[...] é preciso gerar uma infraestrutura fixa capaz de sustentar toda a dinamicidade desse fluxo - para mim, isto é urbanização. Urbanização se trata de construir um cenário que sustente a produção e a circulação de capital. (Ibid., p. 64)

Para o autor, é indispensável analisar a conexão entre capitalismo e urbanização que gera massivas desigualdades sociais e degradação ambiental, além da perda de controle das pessoas sobre as condições que realmente governam suas vidas cotidianas. Como desafio, necessitamos de formas de gestão diferenciadas para cada região e instituições, capazes de promover uma influência coletiva sobre os ambientes construídos.

Tendo em vista essa bibliografia mais recente e baseando-se em levantamentos empíricos, a pesquisa observa que, no final do século $X X$, áreas com economia avançada apresentam intensificação das dinâmicas de dispersão urbana. Contudo, a produção intensa de usos ligados à economia moderna tem gerado a perda gradual da principal característica morfológica que identifica, no território, as dinâmicas de dispersão urbana, que é o esgarçamento ou a descontinuidade do seu tecido urbano.

Essa nova morfologia urbana que aos poucos se manifesta é decorrente dos avanços da reestruturação produtiva ou do contínuo processo de transformação da economia capitalista, que busca constantemente garantir a manutenção da acumulação do capital.

Avançamos da universalização dos mercados e dos modos de produção - que levou à dispersão e fragmentação industrial e à extensão das regiões metropolitanas - para a universalização dos modos de consumo padronizados que tem fortalecido o setor terciário em centralidades de menor porte e intensificado a possibilidade de residir distante dos grandes centros metropolitanos.

Dentre as ocupações ligadas à economia contemporânea, além da busca constante de novas fronteiras imobiliárias - ou seja, do incremento da atuação do mercado imobiliário que cada vez mais distribui pelo território produtos padronizados como os condomínios residenciais fechados -, observa-se a intensificação de ocupações ligadas à modernização do terciário (shopping, hipermercados, locais de evento, malls, centros empresariais, condomínios industriais e logísticos, escolas, universidades e grandes cadeias comerciais que passam também a se organizar em rede, algumas com alcance global). Além disso, a mecanização da agricultura e da pecuária, que já permite a produção em pequena escala sem grandes extensões territoriais, também passa a se localizar dentro das áreas urbanas.

Esses novos usos modernos vêm promovendo uma ocupação acelerada dos espaços intersticiais resultantes das dinâmicas anteriores de dispersão urbana e, portanto, a junção 
ou aproximação de territórios dispersos. Como resultado desse processo, manifesta-se um tecido urbano cada vez mais contínuo, porém ainda fragmentado, ou seja, sem relação com seu próprio entorno ou com núcleos urbanos contíguos.

Essa nova morfologia urbana, cuja continuidade territorial não se originou da expansão de um núcleo ou centro, mas da aglutinação de áreas dispersas que, em sua maioria, não se relacionam na escala local, pressupõe, assim, a permanência das mesmas condições de fragmentação territorial encontradas na organização espacial dos territórios dispersos ou territorialmente descontínuos. Ou seja, são tecidos que, embora apresentem continuidade territorial, são territorialmente e espacialmente fragmentados.

Conforme Spósito (2007), o conceito de descontinuidade ou continuidade territorial se difere do conceito de continuidade ou descontinuidade espacial. Muitas vezes a descontinuidade do território só é possível porque existe continuidade ou integração espacial, o que produz um território fragmentado, que só se viabiliza devido à existência de infraestruturas de saneamento e transporte e, principalmente pelas tecnologias de comunicação, que permitem conexões que ultrapassam os limites físicos territoriais, mas não garantem que as relações de entorno, bairro e núcleo contíguos se estabeleçam.

Segundo Reis (2015), quanto mais especializado um lugar, maior seu consumo e maior sua inserção nas novas dinâmicas da economia moderna e, portanto, mais nitidamente se observam as recentes dinâmicas de dispersão e transformação urbana. As novas dinâmicas podem ocorrer em qualquer dimensão territorial, independentemente de porte e de dados populacionais, e devem ser analisadas, cada uma dentro do seu contexto socioeconômico.

Conforme Castells (1999), quanto maior a inserção de uma aglomeração urbana na economia moderna, maior será o papel de seus serviços avançados e maior será a reestruturação do seu espaço urbano. Da mesma forma, as economias menos avançadas manterão uma estrutura urbana mais tradicional e rígida, sem grandes alterações em suas dinâmicas urbanas

0 que parece certo é que essas formas mais avançadas de urbanização se manifestam em áreas com localização estratégica, atendidas por infraestruturas de transporte e comunicação que atraem o desenvolvimento de uma economia mais avançada que, por sua vez, requer facilidade e agilidade de conexões e deslocamentos e, dessa forma, garanta integração espacial.

Ou seja, as transformações contemporâneas na forma urbana estão intimamente relacionadas com a alteração e a intensificação nas dinâmicas de comunicação e mobilidade. A intensificação das ocupações dispersas ou das formas mais avançadas de urbanização, decorrente de transformações econômicas e avanços técnicos, altera e estende a escala das relações sociais, produzindo interações sociais que vão muito além das relações citadinas ou metropolitanas, provocando uma regionalização do cotidiano que acompanha a dispersão das atividades industriais modernas, do lazer, do comércio, dos serviços avançados e dos empreendimentos imobiliários (Reis, 2006).

Segundo a análise de Indovina (2004), a diferença entre a cidade difusa (transformação urbana na região do Vêneto devido ao avanço 
das áreas urbanas sobre áreas rurais) e a área metropolitana está em suas hierarquias. $\mathrm{A}$ área metropolitana estende-se por um território fortemente hierarquizado, um centro (a grande cidade) e suas cidades-satélites pequenas e médias (difusas no território circundante), ou seja, um território caracterizado principalmente por conexões verticais, nas quais as ofertas urbanas (localização das atividades, deslocamento da população e outros) são hierarquizadas e, portanto, mais excludentes.

Já a cidade difusa, segundo a visão de Indovina (ibid.), pressupõe uma organização espacial caracterizada por conexões horizontais menos hierarquizadas que a área metropolitana, com formação de novas centralidades, apesar de gerarem problemas do ponto de vista ambiental, de infraestrutura e fragmentação.

Este artigo atenta para um estágio mais avançado no processo de urbanização, que gera o fortalecimento dessa organização espacial dispersa, policêntrica e já abastecida por redes de infraestruturas. Esta organização cada vez mais apresentará uma articulação hierárquica urbana mais equilibrada, devido a intensificação e complexidade de suas relações econômicas e sociais, que se tornam, cada vez, mais autônomas e insubordinadas a uma única e exclusiva centralidade tradicional.

Conforme exposto, do ponto de vista da escala local ou do tecido urbano, evidencia-se a perda gradual da principal característica das dinâmicas de dispersão, que é o esgarçamento do tecido urbano. Do ponto de vista da escala regional, o adensamento de usos ligados ao avanço da economia moderna bem como o aumento de mobilidade cada vez mais fortalecem centralidades, escalas ampliadas e relações macrometropolitanas.
A partir deste século, áreas estrategicamente localizadas que se inserem no padrão de urbanização avançado ou de intensificação das dinâmicas de dispersão urbana evidenciam, além de uma alteração na morfologia do seu tecido urbano, alteração na direcionalidade e na demanda de seus fluxos de deslocamento, que se tornam multidirecionais, relacionando-se com mais de uma centralidade.

Ainda, a relação de importância que se estabelece entre deslocamentos físicos e as conexões virtuais tende, muito gradualmente, a se aproximar de um equilíbrio. Conforme Domingues (2007), a rodovia criada para aumentar a velocidade dos deslocamentos, atualmente, produz atritos por congestionamentos.

Do ponto de vista do deslocamento da produção, as infraestruturas físicas continuam estruturando e sendo imprescindíveis para a movimentação de produtos e mercadorias, porém, do ponto de vista do consumo e do trabalho, as tecnologias de comunicação são cada vez mais necessárias e vêm aos poucos substituindo os deslocamentos físicos.

À medida que as novas tecnologias vão sendo incorporadas à sociedade e à produção, aceleram a transformação das relações sociais que passam a ocorrer em escala global, através do aumento dos fluxos de deslocamentos diversificados, multidirecionais e virtuais, expandindo e tornando cada vez mais complexo o entendimento das novas dinâmicas urbanas.

Castell (1999) defende que, com a tecnologia da informação facilitando as relações sociais e de trabalho e permitindo o intercâmbio de informações em tempo real, sem a necessidade da proximidade física dos grandes centros de negócios, serviços e lazer, estabelece-se uma 
nova lógica espacial, sem forma definida, e que se viabiliza tendo, como principal característica ou estrutura, o espaço dos fluxos.

0 que o artigo sugere é que as formas mais avançadas de urbanização em processo de modelação, sejam estas indefinidas, dispersas, descontínuas ou difusas, vêm apresentando contornos e limites territoriais mais nítidos, embora ainda sejam bastante complexas do ponto de vista de suas relações espaciais.

0 que permanece, tanto nas dinâmicas de dispersão urbana como nas formas mais avançadas de urbanização, é que ambas estimulam a produção de um espaço urbano conectado muito além da proximidade física, embora cada vez mais diferenciado em termos sociais, ou seja, cada vez mais territorialmente segregado.

Barreiras físicas e sistemas de segurança mantêm distantes diferentes classes sociais. A infraestrutura bem como as áreas públicas e institucionais dos novos condomínios não são estendidas para as áreas adjacentes ocupadas por população de mais baixa renda.

Ainda que esses novos espaços estejam conectados a redes globais, estas são internamente desconectadas das populações locais, o que caracteriza a produção de uma nova dimensão urbana. "Há coisas próximas que não se tocam, há coisas longíguas que se relacionam. Há relações que não se reproduzem no interior de um determinado espaço" (Domingues, 2007, p. 230).

A questão que se coloca, diante dessas alterações morfológicas e de mobilidade, é se, a partir do século XXI, ainda podemos falar em dispersão urbana como expressão espacial decorrente do processo de evolução e intensificação do processo de reestruturação produtiva.
A forte atuação do mercado imobiliário, a modernização da indústria, o crescimento do número, tamanho, importância, poder e integração das grandes cadeias do setor de serviço, bem como os complexos agroindustriais, ou seja, o avanço e a exploração de todas as possibilidades de produção e consumo em escala global, têm alterado a lógica territorial e espacial.

0 que se conclui é que, partir de 2000, se inicia a configuração de um novo estágio de produção do espaço capitalista, decorrente da intensificação dos processos de reestruturação produtiva, da globalização e da intensa incorporação das telecomunicações pela sociedade e pela produção.

Conforme Domingues (2007), necessitamos encontrar novas formas para denominarmos as novas coisas, evitando levar ao limite o processo de reciclagem de conceitos que vêm de um momento anterior e que pertencem a um mundo diferente. 0 problema já foi identificado, agora é preciso criar consensos nas diferentes esferas do poder público sobre hierarquias de decisões, na tentativa de compreender as novas questões advindas desse processo.

Considerando esse território, contínuo e fragmentado, porém espacialmente integrado que prevalece na contemporaneidade, a questão que se coloca é como gerir o que é público e deve ser partilhado por muitos, como obter consensos entre os reais usuários dentro de um processo que vem apresentando formas mais avançadas de urbanização, tendo em vista a nova lógica dos espaços de fluxos, em que a sociedade se relaciona em múltiplas dimensões que vão além dos limites administrativos estabelecidos, ao mesmo tempo que não se relaciona com o espaço físico que ocupa ou com seu entorno local. 
A partir do exposto, e tendo em vista 0 vetor noroeste paulista, observa-se, a partir de 2000, devido aos avanços da economia capitalista ou à intensificação das dinâmicas de reestruturação produtiva, a produção de novas formas de tecido urbano nesse vetor, que começam a assumir características morfológicas distintas daquelas apresentadas pelas tradicionais dinâmicas de dispersão urbana.

\section{Dispersão urbana e reestruturação produtiva no vetor noroeste}

A partir da década de 1990, a reestruturação produtiva apoiada na globalização permitiu que conexões mais velozes e instantâneas de pessoas, mercadorias, informação e capital se estabelecessem entre as regiões metropolitanas de Campinas e de São Paulo. Em 1998, iniciou-se a construção do Rodoanel, que junto ao Sistema Anhanguera/Bandeirantes, daria suporte espacial à reestruturação da economia.

A incorporação de novas tecnologias de informação permitiu maior flexibilidade nas localizações industriais, possibilitando a sua fragmentação, ou seja, a separação entre gestão e produção industrial.

Atividades antes desenvolvidas no interior das fábricas, como gestão, controle financeiro, automação de processos, seleção de pessoal, logística e distribuição, são terceirizadas e distribuídas pelo território, com ênfase para os eixos rodoviários, impactando o vetor noroeste paulista estruturado pelo sistema de rodovias Anhanguera/Bandeirantes.
Agora, é a nova indústria advinda do setor terciário (tecnopolos e os centros de abastecimento e logística) que se fragmenta e se dispersa pelo território, ocupando grandes áreas dispersas e de baixa densidade ao longo de todo eixo da rodovia Anhanguera. Predominam, a partir de então, as indústrias de tecnologia, bem como uma significativa quantidade de centros terceirizados de abastecimento e logística, decorrentes dos processos de fragmentação e terceirização industrial.

Esse processo é acompanhado pela intensificação das dinâmicas de dispersão urbana e dos deslocamentos urbanos cotidianos que são suportados pelos novos eixos rodoviários pós-década de 1970 e pelas novas tecnologias de comunicação que, além de permitirem a fragmentação da indústria, passam a garantir a possibilidade real de trabalhar e residir distante dos grandes centros metropolitanos.

Observa-se, na Via Anhanguera, além da transformação dos antigos condomínios de chácaras, lazer de fim de semana, em condomínios residenciais, uma intensa produção imobiliária de novos loteamentos e de condomínios residenciais.

A intensificação das relações socioeconômicas, bem como dos deslocamentos urbanos cotidianos no sistema Anhanguera/ Bandeirantes, principalmente entre a Região Metropolitana de São Paulo (RMSP) e a Região Metropolitana de Campinas (RMC), institucionalizada na década de 1990, criou uma dinâmica uniforme que passou a caracterizar essa região do estado.

Esse desenvolvimento ocorreu também nos demais vetores de expansão da capital e, embora cada um possua suas especificidades, uma dinâmica uniforme passa a caracterizar 
esse macroterritório que se estende além da região metropolitana de são Paulo, resultando na configuração de uma nova escala territorial.

Em 1992, a Emplasa, tendo em vista a extensão das relações socioeconômicas da metrópole paulista e para melhor gestão e desenvolvimento dessa região metropolitana estendida, denomina-a Macrometrópole Paulista. Atualmente, esse complexo compreende as regiões metropolitanas de São Paulo, Campinas, Baixada Santista, Sorocaba, Vale do Paraíba e Litoral Norte, bem como as aglomerações urbanas de Jundiaí e Piracicaba e a unidade regional de Bragantina. Tem como principal eixo de desenvolvimento o vetor noroeste, estruturado pelo moderno sistema de rodovias Anhanguera/Bandeirantes.

Não se pode ignorar a conformação desse macroterritório, estruturado por eixos rodoviários, produtivos e regionais, que permitiram intensificação e ampliação das relações socioeconômicas da escala metropolitana à regional.

Melhorias e modernizações no sistema Anhanguera/Bandeirantes, a conclusão do trecho oeste do Rodoanel, a expansão do aeroporto de Viracopos e do porto de Santos viabilizam, a partir de então, a transformação do sistema Anhanguera/Bandeirantes em um importante corredor regional ou macrometropolitano, de mobilidade nacional e de intenso desenvolvimento industrial e urbano.

A via Anhanguera passa a atrair o mercado imobiliário para novos usos ligados à economia moderna, como o setor de serviços avançados, os tecnopolos, além dos condomínios residenciais e industriais fechados. A rodovia dos Bandeirantes, autoestrada fechada, assume a função de principal vetor de mobilidade urbana do Estado.

Indústrias de tecnologia instalam-se na região de Campinas (Dell, IBM, Huawei) e Jundiaí (Foxconn, Itautec, Aoc e Mahle). Ademais, uma significativa quantidade de centros terceirizados de abastecimento e logística passa a ocupar grandes áreas dispersas ao longo do eixo da rodovia Anhanguera, entre a capital e Campinas, estendendo-se, a partir do século XXI, também para a rodovia Bandeirantes.

Observam-se antigas áreas industriais caracterizadas pela indústria leve de bens de consumo associada a recursos naturais, empregadora de numerosa mão de obra não qualificada, sendo substituídas por grandes centros de abastecimento e logística, além dos avançados tecnopolos e indústrias de ponta, associados a grandes centros universitários de pesquisa e tecnologia e de reduzida, porém, qualificada mão de obra (Eigenheer, 2011).

Os primeiros centros de distribuição de grande porte se instalaram na década de 1990 no eixo Anhanguera: CD Pão de Açúcar (1997) em São Paulo e o CD Casas Bahia (1996) em Jundiaí. Depois se instalaram: Distribution Park Louveira (2000), DHL Supply Chain (2000) em Louveira, CD Marabrás (2006) em Cajamar, CEVA Logística (2004) em Jundiaí, CD Destro Macro Atacado e CLA Centro Logístico Anhanguera em Jundiaí, Jundiaí Business Park (2009), McLANE, no distrito de Perus, ABM CCP Cajamar Industrial Park (2011), Global Jundiaí (2011), Distribution Park Cajamar (2011).

Além dos CDs, advindo dos processos de reestruturação produtiva, verifica-se na via Anhanguera, entre São Paulo e Campinas, a 
presença de mais de 50 empresas com acesso direto pela estrada.

Ao mesmo tempo, verifica-se o aumento de suas ocupações precárias e informais, embora não sejam predominantes no mais importante vetor de desenvolvimento econômico do estado. De qualquer forma, configura-se uma macrorregião heterogênea, dispersa e fragmentada, que tem como principal elemento de mobilidade urbana e eixo estruturador o sistema Anhanguera/Bandeirantes.

Portanto, tendo em vista as facilidades de transporte rodoviário, bem como o progresso tecnológico já incorporado à produção e à sociedade, permitindo, além da contínua modernização da indústria, a ausência de obstáculos em residir fisicamente distante dos grandes centros metropolitanos, intensifica-se o processo de ocupação urbana e industrial desse corredor. Essa alteração na escala metropolitana, que antes polarizava empregos e residências, passa a se constituir de centros polarizadores, em torno de algumas cidades menores.

Conforme veremos a seguir, o avanço e a intensificação dos processos de reestruturação produtiva ou de modernização dos modos de produção e consumo capitalista, intensificam e alteram as relações sociais e as dinâmicas de dispersão urbana, produzindo no eixo Anhanguera novas formas de tecido urbano, objeto de estudo desta pesquisa.

Figura 2 - Indústrias às margens via Anhanguera:

Vinhedo - km 75; Louveira - km 71; Cajamar - km 36
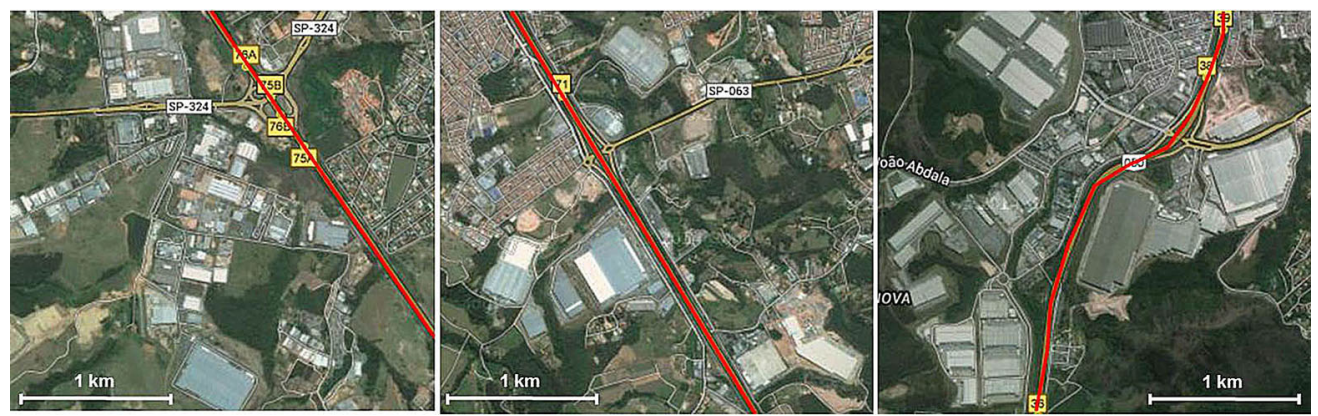

Fonte: Elaborado a partir de imagem: http://maps.google.com.br, acesso em: 6 jan 2017. 


\section{Transformações recentes: avanços nos processos de reestruturação produtiva e novas dinâmicas de dispersão urbana no vetor noroeste}

A partir do século XXI, os processos de dispersão urbana e industrial continuam a ultrapassar os limites metropolitanos, porém, agora, acompanhados também pela dispersão do setor de serviço, que passa a se organizar em rede e advém de mais uma etapa do processo de modernização industrial, ou seja, dos avanços dos processos de reestruturação produtiva.

Ao mesmo tempo, a população de média e alta renda que agora reside distante dos grandes centros metropolitanos, principalmente nos municípios de pequeno porte, como Valinhos, Vinhedo, Louveira e Cajamar, estrategicamente localizados no eixo da rodovia Anhanguera e com melhor oferta de qualidade de vida, passa a requerer um suporte espacial adequado do setor terciário, atraindo também o comércio (cadeias globais que se organizam em rede) e o setor de serviços avançados para esses municípios.

A partir de 2000, intensifica-se ainda mais a ocupação desse território por usos ligados à economia moderna, devido ao progresso tecnológico já incorporado à produção e à sociedade, bem como, às facilidades de transporte rodoviário e à contínua modernização da indústria.

Da universalização dos mercados e dos modos de produção que gerou a extensão das regiões metropolitanas, à universalização dos modos de consumo padronizados que têm fortalecido centralidades de menor porte e garantido a possibilidade real de residir distante dos grandes centros metropolitanos.

Ressalta-se que os usos ligados à economia moderna ou à modernização da indústria estão presentes em todo o vetor noroeste,

Figura 3 - Evolução da mancha urbana do vetor noroeste 1975-2010

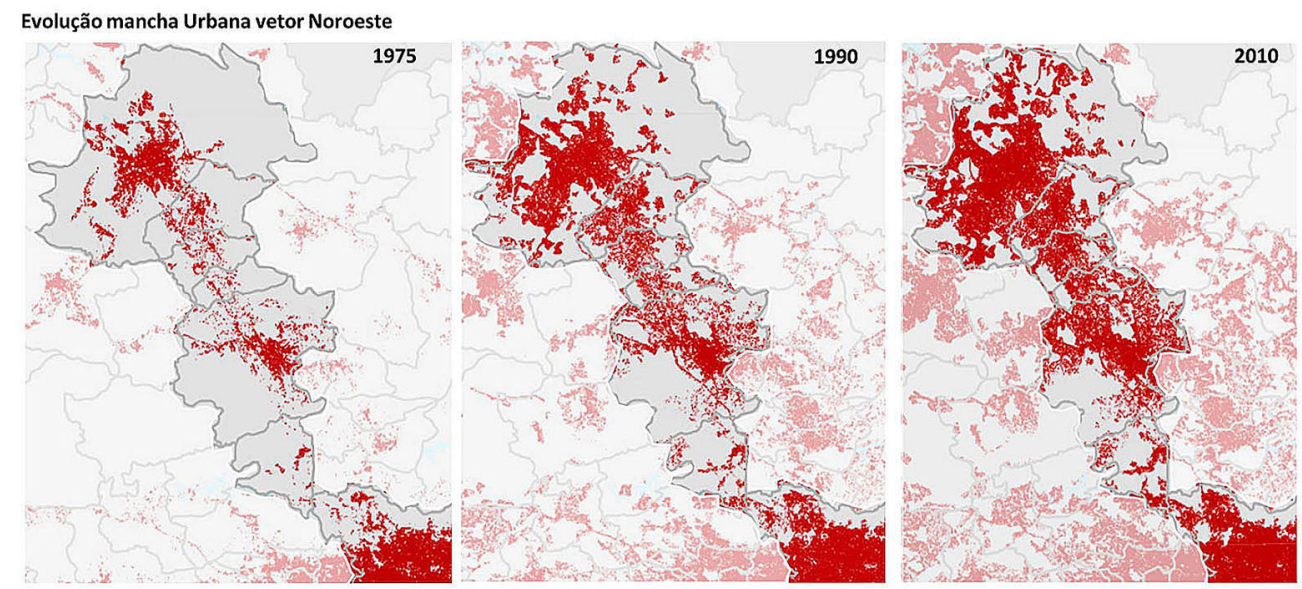

Fonte: Elaborado a partir de imagem cedida pelo Lume - Laboratório de urbanismo da metrópole. 
embora, em municípios de menor porte com localização estratégica e formação recente, elas sejam mais evidentes do que em aglomerações urbanas ou metropolitanas já consolidadas, onde essas ocupações recentes se misturam com ocupações ocorridas em outras etapas do processo de acumulação capitalista.

Novos usos ligados à economia moderna passam a preencher e adensar os vazios ainda existentes, decorrentes dos processos de dispersão urbana.

Além da multiplicação dos condomínios fechados e das indústrias modernas, agora mais relacionadas ao setor de serviços, também o comércio e o setor de serviços são atraídos para o eixo Anhanguera.

Conforme abordagem de Cunha e Miglioranza (2006), a emergência dos condomínios fechados implantados ao longo da década de 1990 e do êxodo em grande escala de pessoas com melhores condições financeiras dos grandes centros (São Paulo, Campinas e outros) para cidades menores e áreas rurais, em busca de qualidade de vida, fez com que a direta relação entre pendularidade e pobreza, que existia no País até a década de 1970, deixasse de existir.

Além da extensão da escala metropolitana, que antes polarizava empregos, residências e comércio, esse processo gera o fortalecimento de novas centralidades, como as cidades de médio e pequeno porte, que se tornam cada vez mais independentes dos grandes centros metropolitanos e sofrem impactos territoriais significativos. Ou seja, intensifica-se a ocupação desse território por usos ligados à economia moderna, acarretando transformações morfológicas e territoriais significativas nos municípios de pequeno porte atravessados pelo eixo Anhanguera.

Figura 4 - Transformações urbanas no município de Cajamar ao longo do século XXI

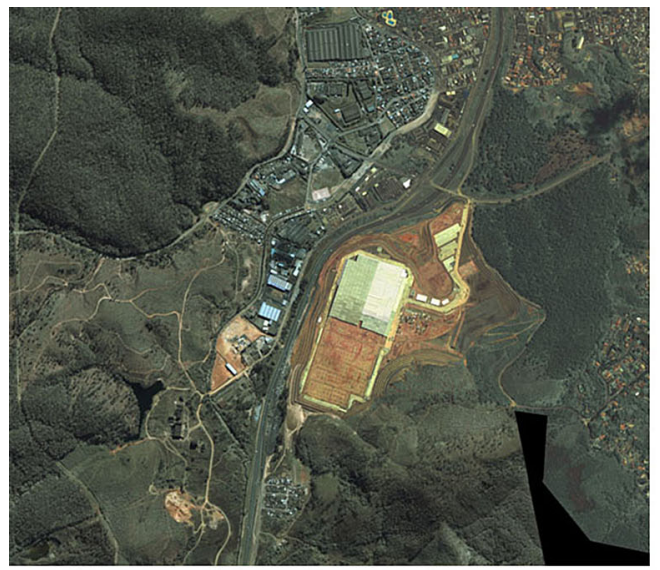

2001-Área às margens da Via Anhanguera

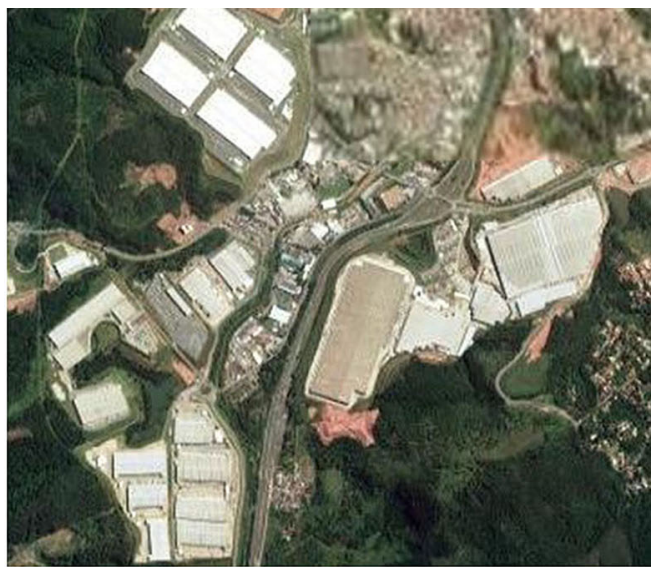

2017-Indústrias e Condomínios Logísticos na Via Anhanguera.

Fonte: Prefeitura de Cajamar e Multispectral (imagem de 2001) e Emplasa geo (imagem de 2017). 
Figura 5 - Transformações urbanas no município de Vinhedo ao longo do século XXI

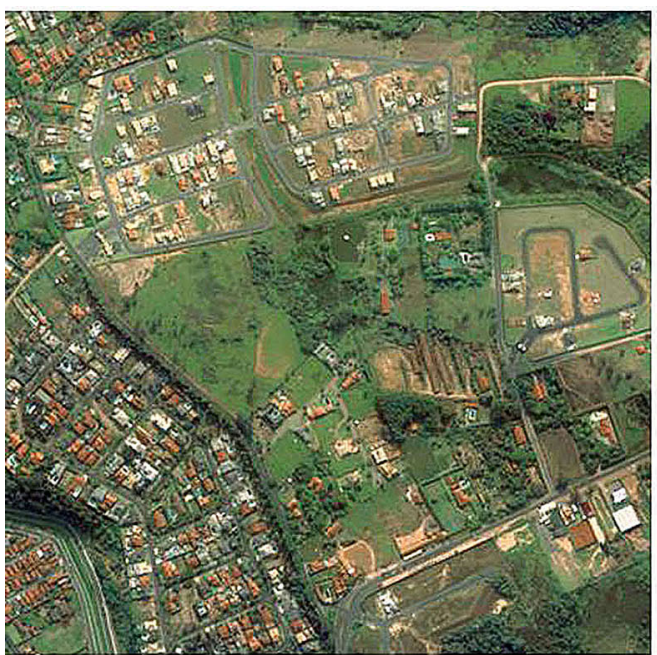

2006 Área residencial condomínios fechados.

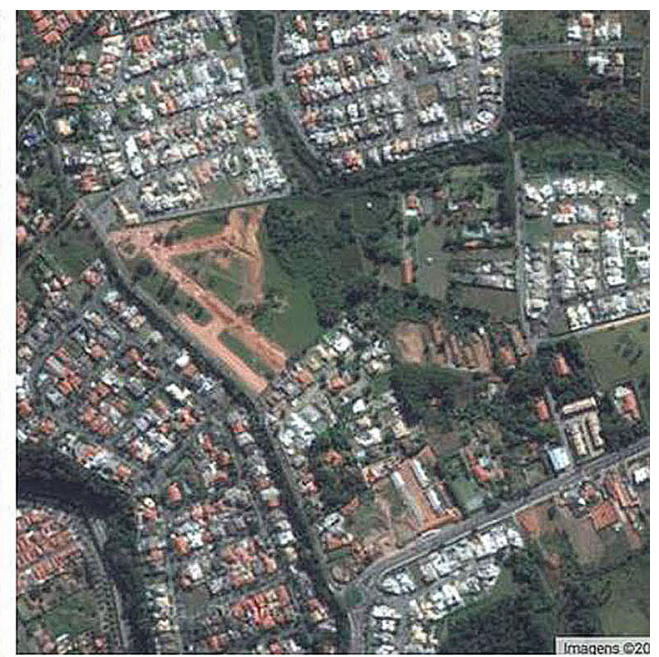

2016 Adensamento territorial e abertura de novos condomínios.

Fonte: Prefeitura de Vinhedo e SSR tecnologia (ortofotos de 2006) e Emplasa geo (imagem de 2016).

0 fortalecimento dessas centralidades de menor porte faz com que elas se tornem cada vez mais autônomas e insubordinadas à polarização de uma única centralidade, como São Paulo, Campinas e Jundiaí. Esse processo reduz os deslocamentos unidirecionais que caracterizam as centralidades metropolitanas tradicionais e aumenta os deslocamentos multidirecionais que passam a ocorrer em escala regional, acarretando aumento de deslocamentos no eixo Anhanguera.

A tendência observada é de transição das configurações territoriais das regiões metropolitanas de Campinas e de São Paulo, polarizadas inicialmente por um único centro urbano bem definido (Campinas e São Paulo), para uma nova configuração regional, caracterizada por aglomerações policêntricas, que aumentam a importância dos municípios de médio porte (Jundiaí) e pequeno porte (Cajamar, Louveira, Vinhedo e Valinhos).

Do ponto de vista regional, esse processo gera o fortalecimento da escala macrometropolitana, cada vez mais estruturada por seus eixos rodoviários, apresentando uma morfologia urbana linear e polinucleada com várias centralidades, em detrimento das áreas metropolitanas tradicionais, que se apresentam de forma centrífuga e mononucleada. 
Figura 6 - Vetor noroeste - inserção à macrometrópole paulista

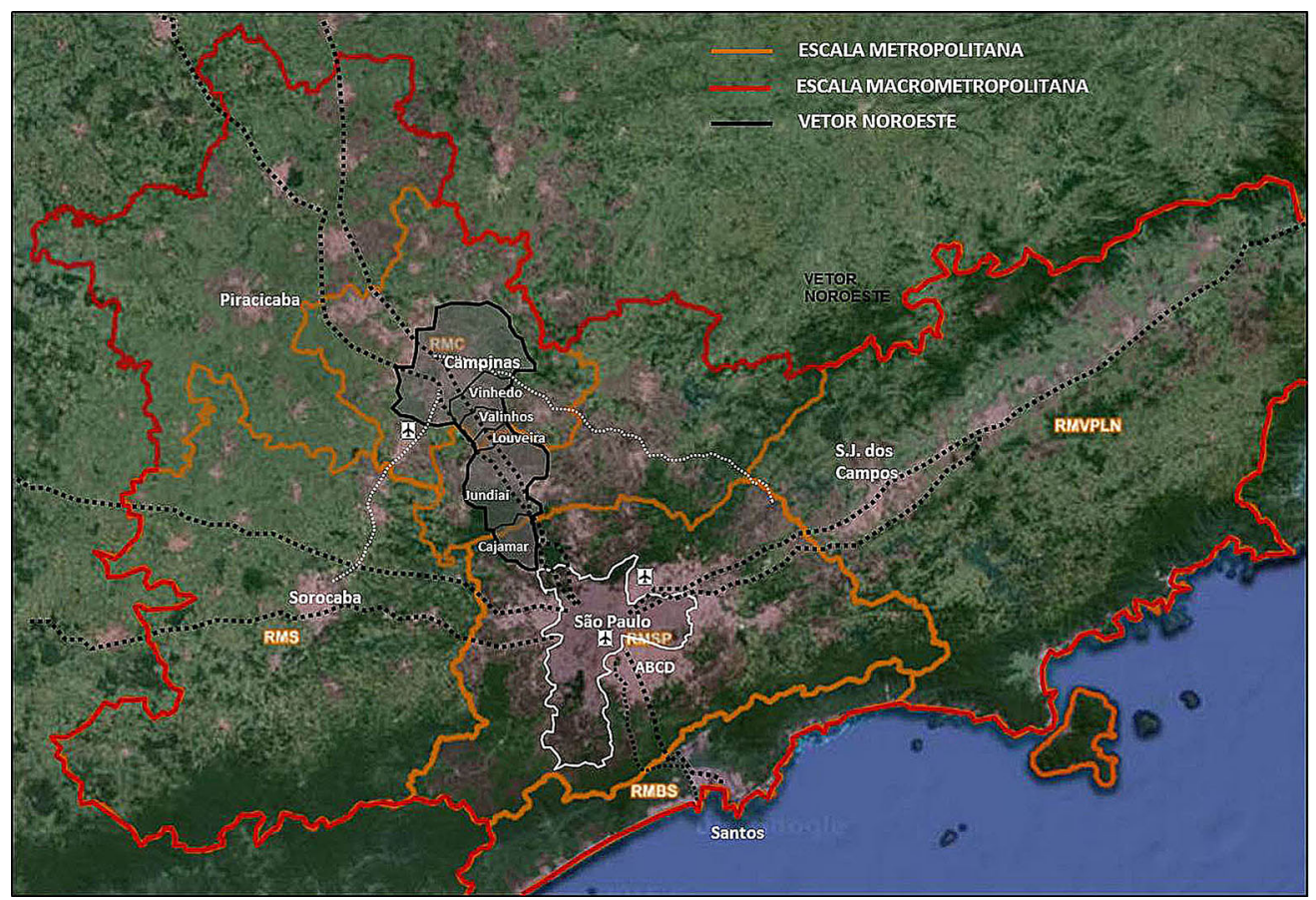

Fonte: Elaborado a partir de imagens http://www.emplasageo.sp.gov.br, acesso em: 15 jun 2016.

Esses municípios terão sua capacidade de desenvolvimento e de atração intensificada quanto maior for sua relação com 0 eixo Anhanguera/Bandeirantes que estrutura e garante a mobilidade dessa região, embora, a partir de 2000, já se observem problemas de congestionamento em ambas as rodovias.

No final da primeira década do novo século, apesar do contínuo processo de investimento e de melhoria realizado pela concessionária privada CCR-Autoban no sistema de rodovias Anhanguera/Bandeirantes, observa-se o aumento dos seus congestionamentos.

A CCR-Autoban passa a conferir um novo padrão de desenvolvimento às rodovias. Porém, ao mesmo tempo que se observam melhorias e investimentos viários no sistema Anhanguera/ Bandeirantes, os custos para o usuário também se tornam cada vez mais altos, restringindo seu uso e ocupação territorial às camadas e setores mais abastados.

Atuando há dezoito no mercado, o grupo CCR é uma das maiores empresas brasileira de concessão de infraestrutura do mundo, com atuação nos segmentos de concessão de rodovias, mobilidade urbana e serviços, com altíssimo valor de mercado. A companhia é responsável por mais de 3000 mil quilômetros da malha rodoviária nacional concedida nos estados de São Paulo, Rio de Janeiro, Paraná e Mato Grosso do Sul. 
Na rodovia Bandeirantes - autoestrada fechada e principal eixo de mobilidade do estado com impacto nacional, problemas de congestionamento e ocupação urbana manifestam-se em suas margens, repetindo o mesmo padrão observado na rodovia Anhanguera, tida como uma estrada fechada, há quase setenta anos, quando foi inaugurada.

Essas transformações econômicas e espaciais têm como suporte espacial imprescindível as infraestruturas de transporte e comunicação, ou seja, observa-se que a evolução técnica das infraestruturas que estruturam esse vetor não acarreta, mas atrai e permite que novos usos ligados à economia moderna se manifestem e fortaleçam novas centralidades, que aos poucos se tornam cada vez mais autônomas e menos subordinadas a aglomerações ou metrópoles tradicionais.

Conforme Vainer (2007), observa-se, no território nacional, a existência de vetores de desenvolvimento e, ao mesmo tempo, de fragmentação territorial. Infraestruturas implantadas com o objetivo de integração territorial, mas que muitas vezes se transformam apenas em espaços mercantis adequados às novas escalas, demandas econômicas e fluxos dominantes, precedem de um planejamento territorial que garanta ordenamento territorial e evite desigualdades regionais.

A análise do vetor noroeste demonstra a necessidade de uma reflexão voltada não apenas sobre o contexto municipal ou metropolitano, mas sobre a regionalização de áreas que se inserem em um mesmo contexto urbano e econômico, a fim de transformar os novos territórios estendidos em um projeto global de reorganização e requalificação do espaço urbano, ao invés do resultado espontâneo de um processo de ocupação sem planejamento que pode gerar entraves futuros.

Conforme Lencioni (2004), a dinâmica metropolitana não é mais exclusiva da metrópole ou da região metropolitana institucionalizada, e essa realidade impõe um novo modo de pensar e de regionalizar o espaço. Além disso, segundo a autora, algumas atividades, até então exclusivas da metrópole, precisam ser replicadas para novas centralidades, para que a reprodução do capital continue sua expansão.

\section{Considerações finais}

Decorrente dos avanços da economia capitalista, evidencia-se, no eixo em estudo, a partir do século XXI uma nova configuração morfológica do seu tecido urbano que se diferencia tanto da continuidade espacial produzida em áreas urbanas que se expandem de forma tradicional, a partir de um núcleo ou centro metropolitano, como da descontinuidade territorial e espacial encontrada inicialmente em tecidos urbanos impactados pelas dinâmicas de dispersão urbana.

Portanto, os processos de dispersão urbana devem ser entendidos como um estágio, que faz parte de um processo mais amplo que vem levando a outras formas mais avançadas de urbanização que apresentam maior continuidade e coesão territorial, embora ainda fragmentados espacialmente.

Do ponto de vista regional, concluímos que novas formas de governança com políticas públicas diferenciadas são necessárias para entendimento e gestão integrada dessa região, estruturada pelo maior vetor econômico do estado. 
Figura 7 - Municípios atravessados pelo eixo Anhanguera

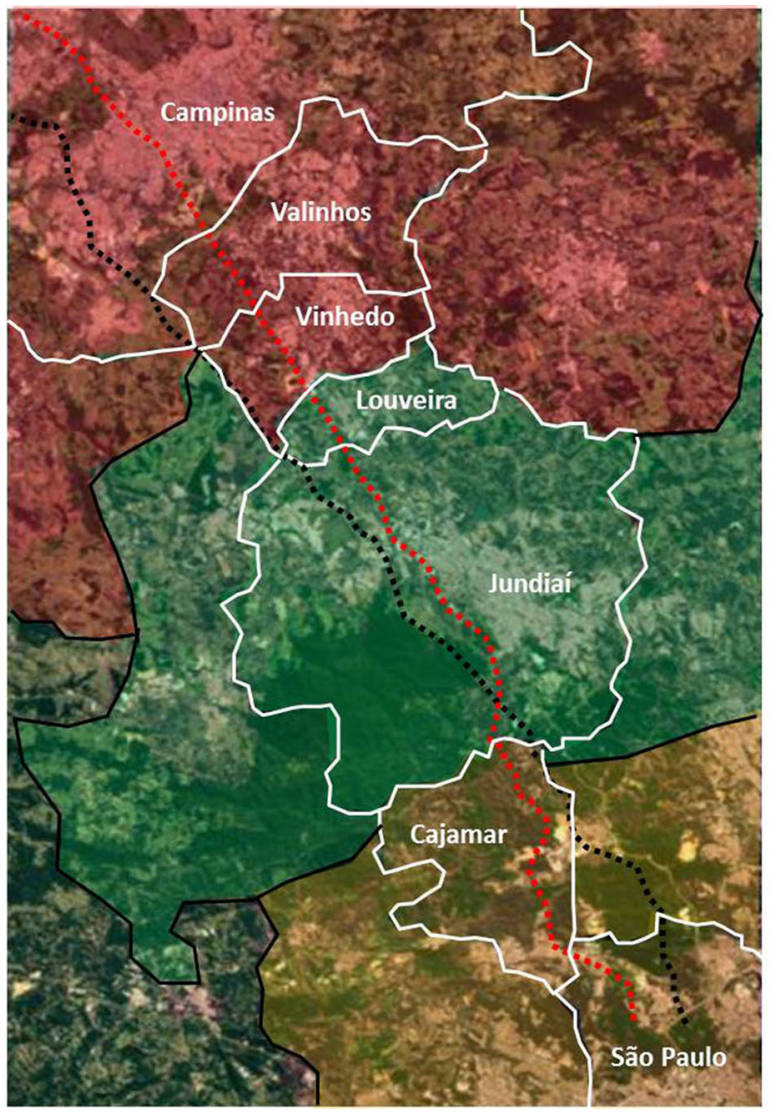

Região Metropolitana de Campinas

Aglomeração Urbana de Jundiaí

Região Metropolitana de São Paulo

Fonte: Elaborado a partir de imagens http://www.emplasageo.sp.gov.br, acesso em 6 abr 2017.

\section{Daniela Maria Eigenheer}

Universidade de São Paulo, Programa de Pós-Graduação em Arquitetura e Urbanismo. São Paulo, SP/Brasil.

deigenhe@gmail.com

\section{Nadia Somekh}

Universidade Presbiteriana Mackenzie, Faculdade de Arquitetura e Urbanismo. São Paulo, SP/Brasil. nadiasom@terra.com.br 


\section{Referências}

BRENNER, N. (2015). Em prol de uma reconsideração do urbano e seu impacto global. Revista Eletrônica de Estudos Urbanos e Regionais. n. 22, pp. 58-67.

CASTELLS, M. (1999). A sociedade em rede. A era da informação: economia, sociedade e cultura. São Paulo, Paz e Terra.

CUNHA, J. M. P. e MIGLIORANZA, E. (2006). “Valinhos: um novo padrão de cidade-dormitório". In: CUNHA, J. M. P (org.). Novas Metrópoles Paulistas. População, vulnerabilidade e segregação. Campinas, Nepo/Unicamp, pp. 539-560.

DOMINGUES, A. (2001). Urbanização extensiva - uma nova escala para o planejamento. CITTA. 1st Anual Conference on Planning Research. FEUP, 30 maio, 2008. Porto.

(2007). "Urbanização difusa em Portugal". Trabalho apresentado ao I Seminário Internacional sobe Urbanização Dispersa e novas formas de tecido urbano. In: REIS, N.; PORTAS, N. e TANAKA, M. Dispersão urbana. Diálogo sobre pesquisas. Brasil-Europa. São Paulo, FAU-USP, pp. 215-243.

(2008). Urbanização extensiva - uma nova escala para o planejamento. CITTA. 1st Anual Conference on Planning Research. FEUP, 30 maio, Porto.

EIGENHEER, D. (2011). Tecnologia, mobilidade e dispersão metropolitana: sistema Anhanguera/ Bandeirantes. Dissertação de Mestrado. São Paulo, Universidade Presbiteriana Mackenzie.

HARVEY, D. (1992). Condição Pós-Moderna. São Paulo, Loyola.

INDOVINA, F. (2004). "La ciudad difusa”. In: Lo urbano: en 20 autores contemporáneos. Barcelona, Ángel Martin Ramos.

LENCIONI, S. (2004). “O processo de metropolização do espaço: uma nova maneira de falar da relação entre metropolização e regionalização”. In: SCHIFFER, S. R. (org.). Globalização e estrutura urbana. São Paulo, Hucitec/Fapesp.

(2015). Urbanização difusa e a constituição de megarregiões. O caso de São Paulo-Rio de Janeiro. Revista Eletrônica de Estudos Urbanos e Regionais, n. 22, pp. 6-15.

MEYER, R. M. P. (2015). São Paulo e seus territórios urbanos contemporâneos. Revista Iberoamericana de Urbanismo. Riurb, n. 12, pp. 7-31.

MEYER, P. G. e LONGO, R. (2015). São Paulo e suas escalas de urbanização. Revista Iberoamericana de Urbanismo. Riurb, n. 12, pp. 1-6.

PACHECO, C. A. (1998). Fragmentação da nação. Campinas, Unicamp.

REIS, N. G. (2006). Notas sobre urbanização dispersa e nova formas de tecido urbano. São Paulo, Via das Artes.

(2007). "Um diálogo importante". Trabalho apresentado ao I Seminário Internacional sobre Urbanização Dispersa e novas formas de tecido urbano. Publicado In: REIS, N.; PORTAS, N. e TANAKA, M. (coords.). Dispersão urbana. Diálogo sobre pesquisas. Brasil/Europa/SP, FAU-USP, pp. 7-31.

(2015). Transcrição da disciplina AUH 5828. Questões de História da Urbanização. Ministrada de 23 a 31 de julho. São Paulo, FAU-Maranhão. 
SOJA, E. (2013). Para além de postmetropolis. Revista UFMG, n. 20, pp. 137-167.

SPÓSITO, M. E. B. (2007). "Descontinuidades territoriais e novas morfologias urbanas no Estado de São Paulo". In: REIS, N. G.; PORTAS, N. e TANAKA, M. S. (orgs.). Dispersão urbana: diálogo sobre pesquisas Brasil - Europa. São Paulo, LAP-Laboratório de Estudos sobre Urbanização, Arquitetura e Preservação da FAUUSP.

(2009). “Urbanização difusa e cidades dispersas: perspectivas espaço-temporais contemporâneas”. In: REIS, N. G. (org.). Sobre a dispersão urbana. São Paulo, Via das Artes/FAUUSP, pp. 38-54.

VAINER, C. B. (2007). Planejamento territorial e projeto nacional. Os desafios da fragmentação. Revista Brasileira de Estudos Urbanos e Regionais (Anpur), v. 9, pp. 9 -23.

\section{Webgrafia}

EMPLASAGEO: Empresa Paulista de Planejamento Metropolitano e Geoinformação ao cidadão. http:// www.emplasageo.sp.gov.br.

Texto recebido em 30/maio/2017

Texto aprovado em 22/ago/2017 
